\title{
Modifications to a Senior Capstone Program to Improve Project Manage- ment and Design-Cycle Pedagogies and Enhance Student Learning
}

\section{Mr. Cory Mettler, South Dakota State University}

Cory Mettler has been an Electrical Engineering instructor at South Dakota State University since 2005. During much of that time, he was employed in industry and was acting as an adjunct for the University. He developed and managed a microelectronics division for an R\&D firm who specialized in Nondestructive Testing analysis. He also was employed as the Chief Sales and Marketing Officer for a consulting firm who specialized in time-domain simulations of distributed generation renewable energy facilities. Today, he leverages his experience managing projects in industry to develop an extremely realistic senior capstone program at SDSU. Cory has also developed or implemented numerous active and experiential learning opportunities in a number of 200- and 300-level electrical engineering courses.

\section{Dr. Robert Fourney, South Dakota State University}

Bob Fourney is an Associate Professor at South Dakota State University, where he has been teaching since 2003. He teaches the digital design and embedded systems portion of the Electrical Engineering curriculum and serves as both a formal and informal advisor for the microcontroller and computer aspects of many senior design projects. He helped to design a two-course freshman experience to complement the improvements in the capstone Senior Design sequence and is preparing to revise the freshman sequence in response to recent curriculum changes. 


\title{
Modifications to a Senior Capstone Program to Improve Project Management and Design Pedagogies and Enhance Student Learning
}

\begin{abstract}
Improvements have been made to an Electrical Engineering Senior Capstone sequence. Improvements include the addition of a supporting course, development of department guidelines to formalize project acceptance, new industry and academic partnerships, and significant modifications to course content. This effort began three design cycles ago and continues to produce successful results.

An Engineering Economics course was unpopular with both students and faculty because it lacked significant substance and was often taught in such a way that students had difficulty relating the material to industry assignments after graduation. Therefore, this course was modified to become a supporting course for the Senior Capstone and now contains both engineering economics and project management material. Learning Objectives in the first half of the course focus on project management material which directly relates to the students' Capstone projects. The topics added to the course include selected items from the Initiating, Planning, Monitoring, Executing, and Closing Process Groups, with the primary focus on the Planning Processes and very minimal focus on the Closing Processes. The second half of the semester is dedicated to the same Economics topics covered in the original course, but are covered in a much more concise way.

Guidelines for project acceptance criteria were formalized. Among other things, it was determined that more emphasis was needed on developing industry-sponsored and multidiscipline projects. In order to increase the availability of true multidiscipline projects, a formal agreement was formed with the Mechanical Engineering Senior Capstone program to create official multidiscipline teams in which both groups of students now report to a single faculty member. Many new partnerships were also developed with industry to increase the penetration of sponsored projects. These projects all are required to have clearly specified requirements at the onset of the project, which makes the assessment of the project management techniques easier to assess.

The original Senior Capstone program was mostly successful, but students did often complain about the workload at specific times throughout the sequence and not all projects were completed on time. Through a more rigorous implementation of project management techniques taught in the supporting course, use of project resources have been more evenly distributed throughout the sequence reducing the student complaint of being overworked. Projects now finish a three weeks earlier allowing time to expose students to an introductory level of system testing and product verification.
\end{abstract}

Results of these modifications have been quite positive. Students gain a more formal understanding of project management while being exposed to more realistic projects. While the 
overall workload has actually increased, that load has been distributed more evenly throughout the sequence and is more positively accepted. Project success rate has been nearly $100 \%$ since the changes were implemented. Additionally, the increase of true multidiscipline projects was favorably noted during a recent accreditation and the increase of industry-sponsored projects have resulted in a number of excellent recruiting opportunities.

\section{Introduction}

Most universities use a capstone senior design course(s) to address ABET's General Criterion 5 which states "students must be prepared for engineering practice through a curriculum culminating in a major design experience" [1]. These programs likely use the capstone course(s) to assess at least some combination of ABET Student Outcomes $3 b$ (design and conduct experiments, analyze and interpret data), 3d (function on multidisciplinary teams), 3e (identify, formulate, and solve engineering problems), and $3 \mathrm{~g}$ (communicate effectively) [1]. In theory, the benefits students gain through exposure to such an experience and the advantages faculty have in using the experience for assessment are substantial and well-documented. However, students who have never managed a large project may struggle with the capstone sequence and poor project-selection can negatively impact faculty's ability to assess the project.

This paper presents modifications made by South Dakota State University's (SDSU) Electrical Engineering (EE) program to enrich the capstone experience. Particular attention was paid to student workload, Industry Advisor Board's (IAB) requests, and ABET requirements. An existing Project Management (PM) and Engineering Economics course was restructured to directly support the capstone sequence, department guidelines were created to help define acceptable projects, and a formal agreement between the EE and Mechanical Engineering (ME) departments was developed to support true-multidisciplinary projects.

\section{Background}

One important factor in the success of a capstone program is the quality of the projects assigned to students. While all curriculums theoretically attempt to expose students to high quality projects, faculty often have difficult agreeing on exactly what constitutes the optimal project. Considering there are many successful, yet dissimilar, models of capstone programs [2], [3], [4], there is not likely to be a one-choice-fits-all solution. However, attempting to accommodate significantly differing opinions within a single course can cause a multitude of problems. For example, if the course instructor is teaching requirement-driven design he or she likely requires a developed Requirements Document. Students working on a research-driven project without well-defined requirements might struggle meeting such course expectations. While both projectstyles potentially result in good projects, equitably assessing both within the same course can prove quite challenging.

While most students tend to respond favorably to their design experiences, it should be recognized that this major design experience does, in fact, introduce a certain level of stress beyond that typically associated with other courses. The size and complexity of projects pursued in most senior design programs are often the most complex project students have experienced at this point in their academic careers. Additionally, many students are stressed when required to formally communicate [5], yet such communication is a common component to senior design. Still others students perceive the team aspect of these projects actually adds to the complexity of 
their design [6]. Many projects falter due to these issues. While some teams overcome and achieve their goals, others fall so far behind they are unable to satisfactorily complete all the project objectives [2]. Students who struggle often do not grasp the underlying causes of their failure and may end up blaming each other, causing additional friction, or otherwise lose motivation.

A solution to many of these problems may be formal project management training [2]. Although project management is a transformative concept in engineering education, it can often be troublesome for learners and, therefore, should be developed through deep learning opportunities [7]. The assumption that students will simply 'pick up' these skills is probably not valid. Even specific course content dedicated to project management, without the opportunity to apply material in a realistic setting, will likely not produce this 'deep learning.'

By their very nature, typical senior design experiences can almost always be classified as Problem Based Learning (PBL). In this pedagogy, students, usually working in teams, take the lead in solving an open-ended, real-world problem; the necessary distinction of PBL is that only after students identify the need for instruction does the instructor provide it [8]. PBL has been shown to develop problem solving, teamwork, analysis, and communication skills [9] making it the natural pedagogy of choice for capstone courses. Since most students recognize the need to manage their capstone project well, they are internally motivated to learn the PM material in order to reduce the difficulty of their capstone projects. Considering the need to apply project management skills to effectively master them, and the natural correlation between PM and design skills, it seems that PBL is also the natural choice for teaching PM material. However, the use of PBL to teach PM is significantly less documented than using PBL to teach design.

\section{Course Histories}

There are three EE courses at SDSU related to the senior design sequence: EE422 Engineering Economics and Project Management, EE464 Senior Design I, and EE465 Senior Design II.

\section{EE464 Senior Design I and EE465 Senior Design II}

The first EE senior design course offerings were piloted at SDSU in 1992 and developed into the modern sequence in 1994. Around this time, the concept spread to the other engineering departments and soon every engineering student at SDSU was required to complete a discipline specific design sequence, consisting of two 2-credit courses. The original intent of these courses was to prepare students for a real-world design experience while adhering to realistic budgets, time constraints, and project requirements. Projects could originate from industry or research programs, but the majority were posed by faculty members. Student were expected to write a project proposal, provide regular status reports, maintain a Gantt chart, and prepare final reports (both written and oral) [10].

Until 2013, teams were consistently comprised of two EE students, a project advisor, and possibly a project customer/sponsor. Course offering typically had 6 to 8 projects, depending on the number of students enrolled in the sequence. Subsequent to 2013, class composition has become much more varied; project teams range from 2 to 6 student with a mix of EE and ME backgrounds, and class sizes vary from 5 to 11 projects. Each project team is assigned at least one project advisor and answers to one industry customer. 
Due to the small size of the EE program at SDSU and the differences in pedagogies used in individual departments, multidisciplinary projects that included students from different programs had been difficult to develop. Therefore, "multidisciplinary" was defined for EE projects as a project that included two distinct fields of electrical engineering [10]. Between 2007 and 2013 only three projects $(5.4 \%)$ were undertaken that consisted of EE student teamed with students from a different program. In all three cases, students from each program were governed by their program's syllabi, meaning that one team might have two completely different sets of course expectations and deliverables. To make matters worse, two teams did not have an integrated PM plan, the lack of which caused conflicting schedules and priorities, as well as a poor understanding of project requirements. The result was infighting among team members and neither project produced a deliverable which met their original specifications. The third team fared slightly better. While still governed by two different sets of course requirements, each team was provided a distinct set of requirements and schedules by the project sponsor. These teams acted autonomously until the final stages of the project. Each team met their respective objectives, but it would be a stretch to consider them a single, multidisciplinary team.

Over the years, the program has seen many incremental improvements and today the program meets or exceeds original expectations in all areas. The sequence has been an effective recruiting tool and is perceived quite favorably by most students [10]. However, as part of the EE department's strategic goals, a number of areas were identified for improvement, including:

1. As more assessment was incorporated into the sequence, and as the project scale increased, the student workload far exceeded the 4 credits allotted to the sequence. As finding more credits in the curriculum was proving difficult, it was desired to reduce the overall workload.

2. Students perceived the limited project management content as "busy work" rather than useful, industry-related skills even as IAB members requested more project management skills from students. It was therefore desired to present PM in such a way that student found it useful and recognized its benefits.

3. It was recognized that there needed to be a balance between multidisciplinary projects that incorporated different EE skills vs projects that took a wider view on the term multidisciplinary. It was desired that at least one project be offered every year that took a more robust view of ABET SO-3d (function on multidisciplinary teams).

In 2013 a faculty member with industry project management experience was hired to primarily focus on these issues.

\section{EE422 Engineering Economics and Project Management}

Until recently, this 2 credit course was simply called Engineering Economics and was unrelated to the senior design sequence. It was an unpopular course for a variety of reasons and was in need of a significant overhaul.

In 2011, under the same course name, the course content was significantly modified. The economics material was reduced to approximately 1.5 credits and taught through traditional methods. The remaining 0.5 credits was used to introduce project management material. A PMI 
certified IAB member performed an intensive seminar to instruct students in this content. A number of good outcomes were achieved, but at this point there was no direct link to senior design.

In 2013, the same IAB member was formally hired to teach the newly created "Engineering Economics and Project Management" course. Through close collaboration with the senior design instructor, a full credit of PM was covered during the first half of the semester while students were initiating their senior projects. During the second half of the semester, the two courses diverged; one course focusing on economics, the other course on design. This was a significant improvement to the course. Much of the PM material covered in EE422, was applied to student design projects during the first half of the semester so students were able to apply what they learned. However, continued reinforcement of that material through the rest of the design sequence proved difficult.

Disconnects caused by expecting students to apply PM material from one course to their senior design projects is a known issue and can be solved by integrating PM material within the design course [11]. Unfortunately, this was not an option at SDSU because the senior design courses already required more student effort than the allotted 4 credits. In 2014 the faculty member hired the previous year to address senior design issues was assigned to EE422 as well as EE464 and tasked to create a more cohesive curriculum between the two courses.

\section{Summary}

Before 2013, the topics covered in the economics class, EE422, had no relationship to senior design and the topic of project management was only covered briefly as part of the senior design course, EE464, Fig 1. Students were expected to write a project proposal that included a Gantt chart and a list of specifications. However, very little instruction was provided on how to build the charts or gather the specifications. Very few students had a cohesive test plan by which their final projects could be evaluated. The topics covered in EE422 did not fully utilize the associated two credits and topics covered in EE464 drastically exceeded a reasonable two-credit workload. A number of topics were presented in lecture, but very little material from those topics were ever incorporated into project requirements. In fact, as Figure 1 also indicates, many of the topics in the actual senior design course (EE 464) were very broad and only applied in a general way, if at all, to many student's projects. This is indicated by the lack of "flow" arrows in that figure. For example, there was a presentation on the topic of "packaging", but each student group had to decide how, or even if, that topic related to their particular project.

In 2013 the first attempt was made to merge project management into EE422. Many important project management topics were discussed in EE422 and some were formally utilized in EE464, Fig 2. In particular, topics such as requirements gathering and scheduling were discussed in detail in EE422 and system engineering and block diagrams were discussed in EE464. Then, a project charter, which incorporated each of these four topics was written. Assessment of the charter affected student's grades in both EE422 and EE464. Another major improvement was requiring a prototype demonstration in EE464, rather than waiting until EE465 to measure actual physical progress. Communication skills required in EE464's design conference presentation were specifically addressed in the communication management section of EE422. A few topics previously covered in EE464 were removed to balance the two credit workloads. These changes 
introduced project management and allowed students to apply some of what they learned to their projects. It also balanced the students' workload and allowed students to begin hardware development in the first semester of the project.

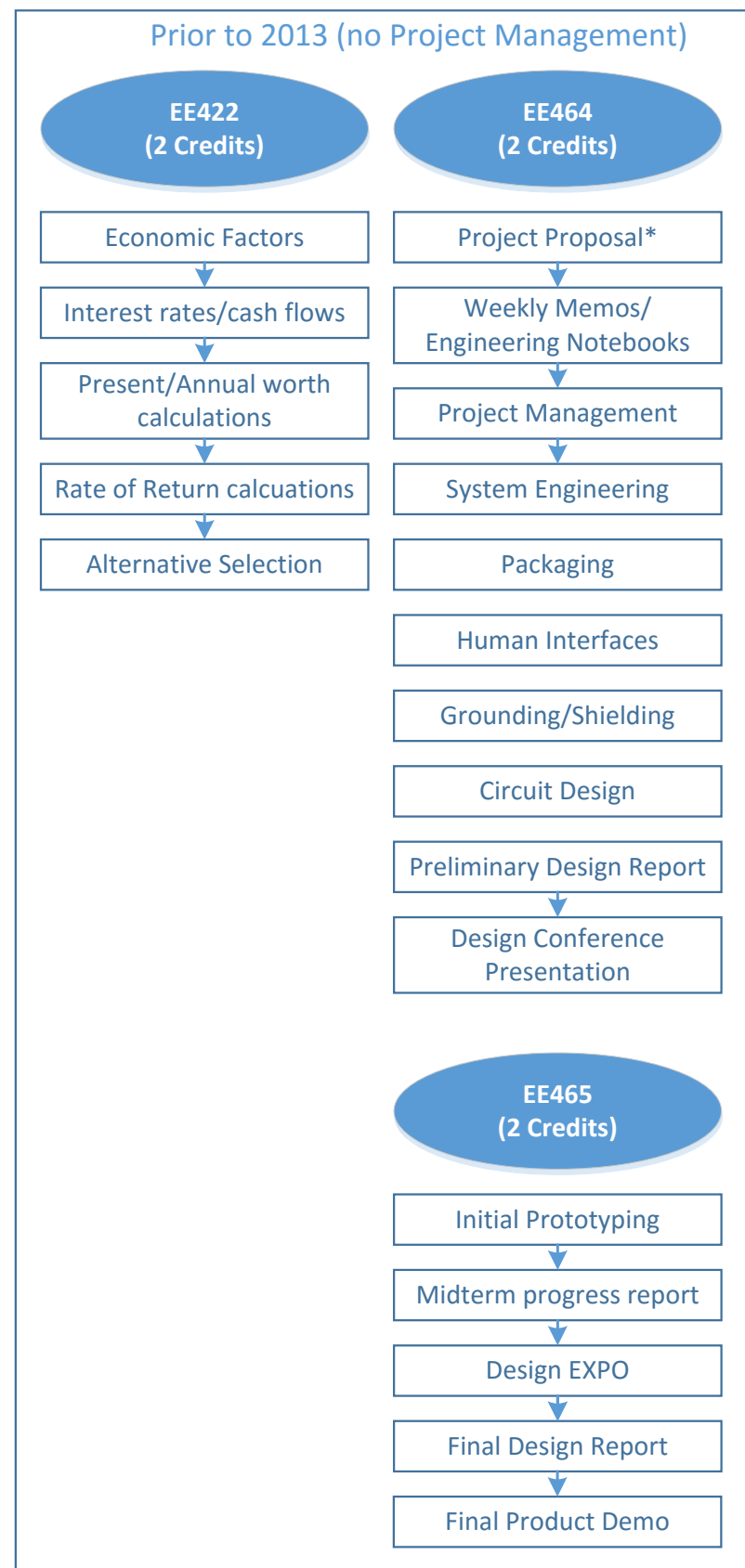

Fig 1. Relationship of topics prior to 2013.

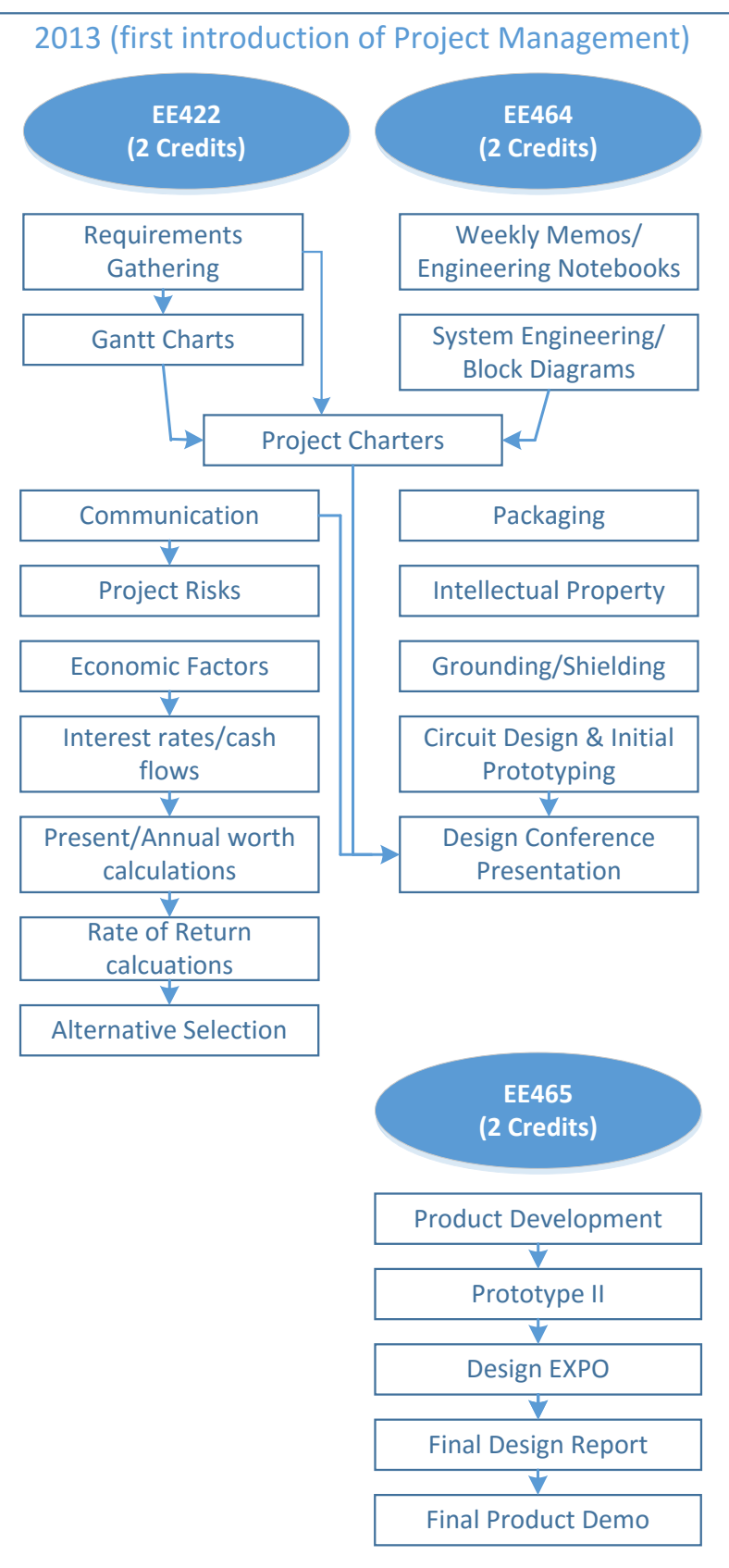

Fig 2. Relationship of topics during 2013 


\section{Methodologies}

Modification were made to the three previously mentioned courses in order to provide a Project Selection Standard, increase the Penetration of True Multidisciplinary Projects, and enrich the Project Management Content, while at the same time reducing the students' overall workload.

\section{Project Selection Standards}

This course takes the philosophy that every project should have a real customer. Most of the recent projects have come from industry sponsors, but a few still come from faculty. Faculty sponsored projects are accepted if they originate from a research program's need; in these cases, the faculty member acts as a customer and does not advise the project. Students' personal projects and purely academic projects are no longer accepted. In this way, the project team (including the faculty advisor) have a customer that holds the team accountable to the agreed upon requirements. Through the interaction with this customers, students are afforded an opportunity to practice communication and other project management skills.

Project selection is a topic which consistently raises a variety of conflicting opinions. Some difficult questions that needed to be answered include:

- Should all projects be hardware based? If not, how much software can be allowed before the project is no longer an EE capstone?

- What is the primary learning objective of senior design? New technical abilities or the design and management process itself? In other words, what constitutes ABET's requirement of "major" design experience?

- How much of the technical design should rely on previous course work? Does only EE course work apply, or could other engineering and mathematics course work be included when assessing the suitability of a project? Does this answer change if students are minoring in an area?

- Are research-based or analysis-based projects acceptable?

- From where should projects originate?

ABET criterion 5 provides guidelines that answer some of these questions, but leaves the exact implementation very open-ended. Brackin and Gibson [12] provide a good example of a screening process that provides excellent interpretation of criterion 5 and was helpful in answer some of these questions. The EE curriculum committee used these two sources as a basis to develop a set of department guidelines that has been effective in screening projects since their implementation. A summary of these guidelines include:

1. Hardware, software, and modeling projects are each acceptable project-types. Electrical engineers may encounter all three of these types of design problems in industry and, as such, these project-types should all be recognized and provided to students to match their individual interests, provided the project meet all of the following criteria.

2. Projects must rely on at least two distinct focus areas of engineering, preferably more. All projects must clearly draw from at least two distinct areas of engineering. Both areas can be specialties of EE, but at least one project each year should draw from another 
source. To the extent possible, given the small class size typical in our program, students with different strengths will be teamed together.

3. Of the two focus areas of engineering, one must be EE-based. In order to guarantee that the project qualifies as an EE capstone, at least of the related fields of engineering must draw from an EE course taught in the EECS's curriculum.

4. Team members must have taken at least two courses related to the project's focus areas. All team members must have completed course work in one of the related fields to complete ABET's requirement that the project rely on previous course work.

5. Technical difficulty in each focus area must be at least as rigorous as that of the course work in those focus areas.

Some might argue that the rigor should be higher than previous course work. However, simply managing a 9-month project is a significant learning experience for students. The objectives for the design course are primarily related to teaching design and management processes. As such, the technical component of the projects must be challenging, but not overwhelming.

6. Project must originate with at least 3 constraints

ABET requires projects to have 'multiple realistic constraints.' By ensuring that the project has 3 realistic constraints, a minimum threshold is enforced. As students progress through their project's Requirements Gathering process, they typically add 3 to 5 more.

7. Project must originate with at least 5 project

ABET criterion 5 states "Engineering design is the process of devising a system... and is a decision-making process...to meet stated needs." Therefore, simply having constraints is not sufficient. Moreover, this statement makes it clear that ABET is looking for design problems, not research or analysis problems. While these are also excellent examples of realistic engineering problems, they just don't apply to Senior Design. As such, a project must have specifications to design towards. Again, the goal here is to verify a minimum amount, but it is expected that most student groups will identify more throughout the project life cycle.

\section{Multidisciplinary Projects}

In order to increase the penetration of projects that include students from multiple programs, an agreement was struck between the EE and ME departments. The primary objective of the agreement was to make sure the entire team was governed by the same set of expectations and that a single, cohesive team was formed. Clauses of this agreement provide:

1. The instructors and department heads of both programs approve the project,

2. Students must volunteer to be on the project team and sign an agreement that they agree to the project, the project team, and all associated conditions,

3. All team members attend class with the instructor who initiated the project and are subject to that instructor's syllabi for the two semester sequence. 
4. The instructor who initiated the project if fully responsible to assign the course grade for all students on the project team.

This policy was piloted in the EE capstone course during the 2013/14 academic year. The team consisted of two ME students, one EE student, and one dual-major (EE/ME) student who acted as the team lead. With the successful completion of the pilot, the departments made the agreement official in 2014 and have implemented it consistently ever since.

While coordination between SDSU's EE and ME programs was the most obvious choice to pilot this concept, other opportunities have been pursued as well. SDSU's Computer Science (CSc) program will be initiating their first senior design program in Fall of 2017 and a similar agreement is in the negotiation process with them. Also, with increasing interest in "precision agriculture", there is potential for development of multidisciplinary project between EE and SDSU's Agriculture and Biosystems Engineering (ABE). However, ABE projects are often not defined until a number of weeks into the school year, whereas EE projects are presented to students on the first day of class. These scheduling conflicts has made implementing a joint project difficult, but negotiations to address the issue have taken place.

\section{Project Management Content}

In an attempt to further enrich the EE422 PM content, the department tasked both EE422 (PM/Econ) and EE464 (Design) to the same faculty member in 2014 and voted that the two become official co-requisites in 2017. This level of coordination made implementation of a PBL pedagogy feasible. Both classes meet 3 consecutive hours per week and for approximately the first half of the semester are directly linked together. General PM topics are covered during EE422 in a lecture style format on Tuesdays for about 1.5 hours.

EE 422 assignments are specific to each individual team's EE 464 project (IE: build a Gantt Chart for your project). Students are given the second half of class to begin to implement their assignments. EE464 is held on Thursdays. Students spend approximately the first half of class presenting oral status reports, typically focused on the PM assignment from the previous week. The remainder of the period is dedicated to project-development.

Since the instructor provides some information in lecture format before students have personally identified the need for instruction, this pedagogy is not truly PBL using a strict interpretation of the method. However, those lectures are intentionally provided at a very general, high level; direct instruction on specific skills is rarely provided. PBL begins to apply after the students struggle with the actual implementation of the concepts and come to the instructor with specific problems; call it "PBL-with-a-kickstart."

An example of how this works: During EE422 on Tuesday, the project management concept of Schedule Management [13] is covered, concepts discussed include:

- Why schedule management is important,

- Definitions of Partitionable vs Non-partitionable activities,

- Guidelines on how to determine whether enough detail is included in schedule,

- Guidelines on sequencing events,

- The course-specific Microsoft Project template. 
During the second part of class, students begin to work on their related assignment: "develop a Gantt Chart for your EE 464 project." Students run into many questions: how should my project be organized, how do I apply dependencies, how much detail is required, etc. The instructor assists in answering questions by giving examples or ideas, but avoids making decisions for the group. Over the next nine days, teams continue to develop the assignment. In EE464 on the following Thursday, students present their work during an oral status report. Feedback is provided from fellow students on the quality of the presentation and their impressions of the Gantt Chart. Shortly after, a draft of the document is submitted for instructor feedback. After that, students are allowed to change the document whenever they feel necessary, but a Revision History is required in order to explain and track the need for the change. Students keep the schedule up-to-date throughout the entire two-semester course of the project, using it consistently to report on project status, and resubmit it for formal assessment six times through the course of the project. The need to continually use the document and the consistent feedback provide many opportunities to master the skill.

A rigorous suite of project management topics is covered during the early stages of the project. Most of which are presented similar to the process used for the Gantt Chart. These include:

- Project Initiation Processes

- SWOT Analysis

○ Requirements Gathering

○ Project Charters

- Team Meeting Expectations

- Project Planning Processes

- Block diagrams

- Gantt Charts

- Risk Registers

- Qualification Plans

- Project Execution Processes

○ Preliminary Design Reviews

○ Prototype demonstrations

○ Critical Design Reviews
- Communication Management

- Escalation Processes

- Revision Control

- Change Order Requests

- Elevator Speeches

- Oral Status Reports

- Written Status Reports

- Conference Presentations

- Project Closure Processes

○ Lessons Learned

○ Final Design Report

- Final Design Presentation

Many of these topics and related assignments are typical of many senior design classes, [2], [3], [11], [12]. However, a number of these topics were developed specifically for these SDSU EECS modifications. Such topics include: Requirements Gathering, Project Charters, Change Order Requests, Preliminary Design Review, Prototype Demonstrations, and Lesson Learned Documentation; further explanation of these important assignments follow.

Requirements Gathering - Teaching Requirement Gathering skills and giving students the opportunity to apply them forces students to think critically about their projects before starting them. This also develops a strong sense of ownership because the students were part of the project development process. 
Project Charters - The Charter is an initiating document that explicitly states the project motivation, scope, and project requirements, it is similar to a Design Proposal. This exercise verifies that project sponsors and student team members have a common understanding and the charter will be the basis for all upcoming design decisions. This document can be used to assess students' ability to communicate effectively (SO-3g)

Change Order Requests - As in industry, senior design projects are often not initially well defined, partly because industry members do not provide perfectly specified projects and partly because students are just learning how to build a requirements document. The instructor only points out weaknesses if they are critical to the success of the project. Our preference is to allow students to work on the project until they realize that certain specifications are poorly written, unachievable, or not applicable. If/when this occurs, the students write a clear explanation of the issue and communicate with all parties involved to get the change approved. This archive can be used to assess students' ability to analyze and interpret data (SO-3b), as well as ability to identify engineering problems (SO-3e).

Preliminary Design Reviews - Toward the end of the first semester students present their paper designs along with any preliminary prototype data to a review panel. This panel consists of faculty with appropriate backgrounds who are not part of the project team. The instructor alone assesses the quality of the presentation. The panel is instructed to focus solely on the quality of design; they are NOT involved in the assessment process. The purpose is to allow students the opportunity to honestly present their ideas and get feedback on their designs before entering the Executing Processes. The students provide a copy of their presentation slides to the panel a few days before the review, present during the review for 20 minutes, and spend 40 minutes in a Q/A session.

Prototype Demonstrations - Teams are required to include prototype demonstrations in their project schedules. Students must propose milestones that show incremental progress and are held accountable to that proposal during each prototype. This structure encourages consistent effort throughout the project life cycle. During the final prototype demonstration, students are required to address each specification in their Project Charter, explain how that specification was tested, and discuss the results of the tests. This process provides additional data on students' ability to design a system or component (SO-3c).

Lessons Learned Documentation - Students are informed early in the project that a Lessons Learned Document will be required at the end of the project and are encouraged to keep notes throughout the project. This document summarizes the lessons learned and includes a discussion on what could have been done differently, student opinions regarding teammates' performance, advisor effectiveness, and the usefulness of the project management component, in addition to any other lessons they have learned. Evaluating lessons learned is an important step in the PBL pedagogy [8]. This document also provides indirect data on students' ability to work in team (SO-3d) and others. 


\section{Summary}

After 2013, the project management material was more fully integrated into project requirements, Fig 3. Currently, the courses start out discussing how to initiate a project by holding a formal kickoff meeting with the purpose of gathering requirements. In EE422, students are required to prioritize those requirements during Scope Control lessons and then taught how to develop Gantt Charts around those priorities. The topics of Block Diagram development and System Engineering are discussed. This is all summarized in a Project Charter. Then, in EE422 topics such as Project Risks, Qualification Plans, and Communication Management are discussed while students begin their initial circuit design in EE464. Students practice the technical communication skills by holding a preliminary design review where they present their project requirements, initial circuit design, project risks, and a qualification plan. After incorporating feedback from the review, they develop and present their first hardware prototype. The requirements document, block diagram risk register, and qualification plan must be presented during this prototype presentation. At the end of the semester students summarize all of these tools at a Design Conference where they again practice communication skills in front of a semi-technical audience. During the second semester students are primarily focused on product development, but they are required to consistently present prototypes throughout the semester. During each presentation, updates to all documents previously mentioned are presented in order to enhance and reinforce techniques previously learned. At the end of the semester students present their projects at a public Design EXPO, write a final design report, and present a Final Product Demo. The Project Charter is used to assess the final product.

\section{Results}

The modifications of interest to this paper started in 2013 and projects initiated between 2007 and 2016 were analyzed for results. Detailed records on projects were not maintained before 2007.

The modifications implemented have doubled the number of projects that originate from real customers; details are summarized in Table 1. Before 2013, the amount of academic projects (those that did not include a real customer) was slightly higher than those customer-based projects. Starting in 2013, only 2 projects have been supported that did not have a non-academic customer.

There are a number of reasons for this change. Commitment to the department goal of increasing industry involvement resulted in a faculty member tasked directly to this issue. Before any of the other modifications had time to take effect, simply having someone dedicated to contacting industry and soliciting projects had significant results. Additionally, demonstrating to potential sponsors the rigor of the project management aspect of the projects provided a level of confidence that if they sponsored a project, it had a high probability of success. As contact with industry increased, certain entities voiced Intellectual Property (IP) concerns that in the past were not always addressed satisfactorily. Through coordination with the University's Technology Transfer Officer, a clear, 1-page statement on the University's IP stance regarding 
the ownership of undergraduate projects was produced. This statement has pacified most concerns related to IP and has been a successful tool in maintaining relationships with industry.

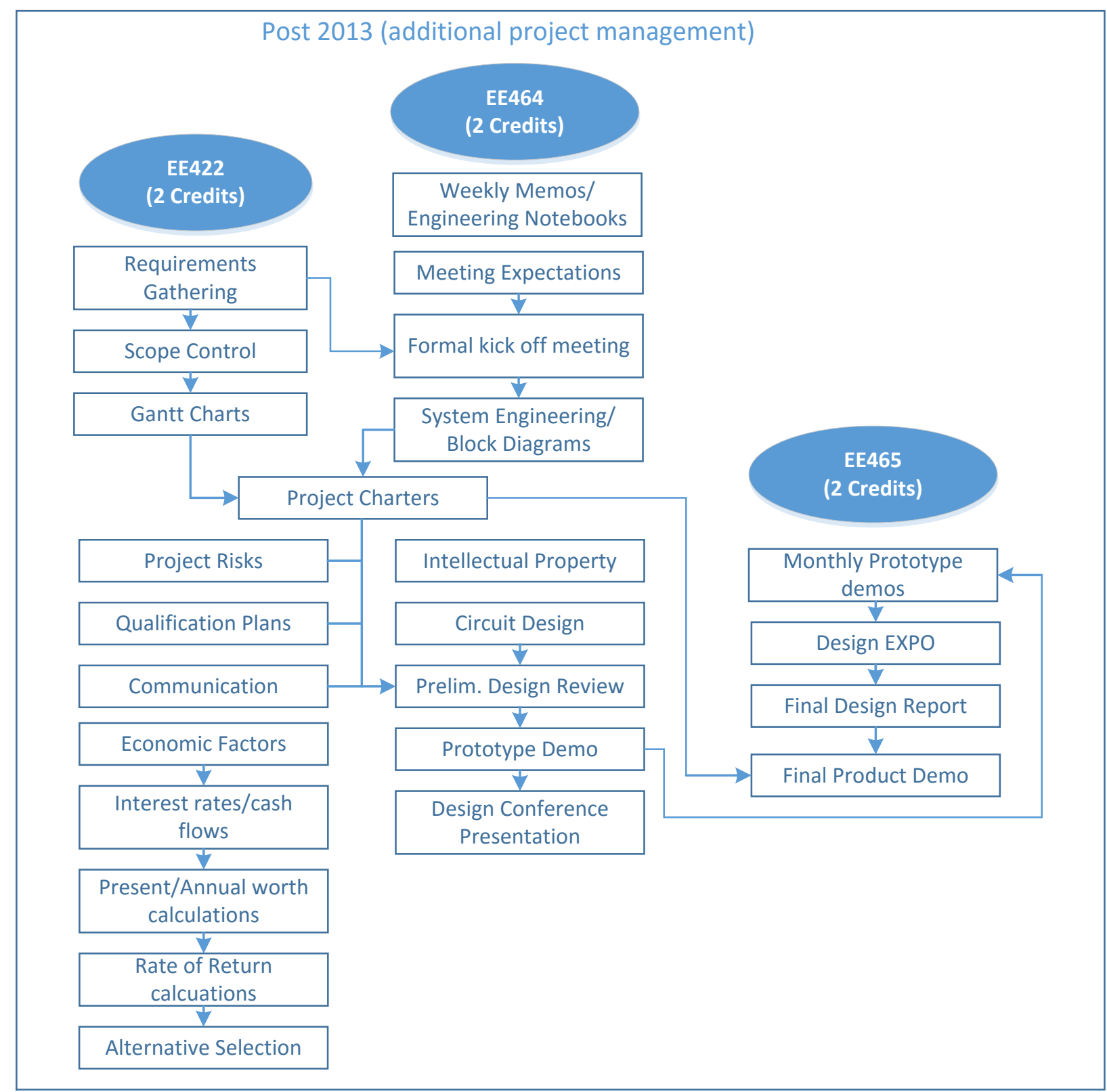

Fig 3. Relationship of topics after 2013 (final)

The number of multidisciplinary projects has also dramatically increased. Table 2 shows the number of project-teams which included students of more than one major before and after 2013. Before 2013, only 3 projects (5.3\% of total) consisted of students from more than one major; only one of those actually met initial project requirements. Since 2013,7 projects $(21.9 \%$ of total) have been performed by true multidisciplinary teams. 
Table 1: Comparisons of projects with and without actual industry customers since 2007.

\begin{tabular}{|c|c|c|c|c|c|}
\hline $\begin{array}{c}\text { Year } \\
\text { initiated }\end{array}$ & $\begin{array}{c}\text { Customer } \\
\text { based }\end{array}$ & $\begin{array}{c}\text { Non-customer } \\
\text { based }\end{array}$ & Total & Percent & Summary \\
\hline 2007 & 3 & 7 & 10 & $30.0 \%$ & \multirow{6}{*}{$46.4 \%$} \\
\hline 2008 & 4 & 7 & 11 & $36.4 \%$ & \\
\hline 2009 & 4 & 3 & 7 & $57.1 \%$ & \\
\hline 2010 & 7 & 1 & 8 & $87.5 \%$ & \\
\hline 2011 & 5 & 3 & 8 & $62.5 \%$ & \\
\hline 2012 & 3 & 9 & 12 & $25.0 \%$ & \\
\hline 2013 & 9 & 1 & 10 & $90.0 \%$ & \multirow{4}{*}{$93.8 \%$} \\
\hline 2014 & 5 & 0 & 5 & $100.0 \%$ & \\
\hline 2015 & 6 & 0 & 6 & $100.0 \%$ & \\
\hline 2016 & 10 & 1 & 11 & $90.9 \%$ & \\
\hline
\end{tabular}

The success of this effort is directly related to the formal agreement between the ME and EE departments. This structured policy gives both sets of students the confidence that a joint project will run smoothly and that they will be treated fairly regardless of which department initiates the project. This, in turn, has created an environment in which students are more willing to accept the additional challenge of working on such projects.

Table 2: Number of projects with team members having differing majors.

\begin{tabular}{|c|c|c|c|}
\hline $\begin{array}{c}\text { Year } \\
\text { initiated }\end{array}$ & Amount & $\begin{array}{c}\% \text { of total } \\
\text { projects }\end{array}$ & $\begin{array}{c}\text { Met/Meeting initial } \\
\text { requirements }\end{array}$ \\
\hline \hline 2007 & 0 & $0.0 \%$ & n/a \\
\hline 2008 & 0 & $0.0 \%$ & n/a \\
\hline 2009 & 0 & $0.0 \%$ & n/a \\
\hline 2010 & 1 & $12.5 \%$ & YES \\
\hline 2011 & 0 & $0.0 \%$ & n/a \\
\hline 2012 & 2 & $16.7 \%$ & NO \\
\hline \hline 2013 & 1 & $10.0 \%$ & YES \\
\hline 2014 & 1 & $20.0 \%$ & YES \\
\hline 2015 & 2 & $33.3 \%$ & YES \\
\hline 2016 & 3 & $27.3 \%$ & YES \\
\hline
\end{tabular}

The effectiveness of introducing project management topics was assessed in a number of different ways. These include direct assessment of students' knowledge of PM tools, students' opinions of PM-effectiveness, and faculty evaluation of student project outcomes.

To assess whether students were mastering the materials, the average class grades of the first formal draft of three different PM tools were compared to the average grade of the last draft. The instructor assessed an informal draft of each document to help students prepare the initial 
content, the assessment of the formal drafts was primarily related to how each team was utilizing the tools in the management of their specific projects. Table 3 shows that students' ability to use the tools improved throughout the course of the projects. Only $2014-2016$ student-groups were used in this analysis. Students from 2013 were assessed on these skills in the fall by the EE422 instructor when the courses were still separated and only the Gantt Charts were used in the spring semester; the 2013-16 cohorts were assessed throughout EE464/465/422 by the same instructor.

Table 3: Improvement of students' mastery of different PM tools

\begin{tabular}{|c|c|c|c|c|c|c|c|c|c|c|}
\hline \multirow{2}{*}{$\begin{array}{c}\text { Proj } \\
\text { Year }\end{array}$} & Class & \multicolumn{3}{|c|}{ Gantt Charts } & \multicolumn{3}{c|}{ Qualification Plan } & \multicolumn{3}{c|}{ Risk Register } \\
\cline { 3 - 10 } & Size & Initial & Final & Improve. & Initial & Final & Improve. & Initial & Final & Improve. \\
\hline \hline 2014 & 14 & $72.2 \%$ & $78.6 \%$ & $6.4 \%$ & $73.4 \%$ & $81.9 \%$ & $8.5 \%$ & $73.0 \%$ & $77.1 \%$ & $4.1 \%$ \\
\hline 2015 & 15 & $70.6 \%$ & $81.3 \%$ & $10.7 \%$ & $71.2 \%$ & $82.6 \%$ & $11.4 \%$ & $81.9 \%$ & $90.7 \%$ & $8.8 \%$ \\
\hline 2016 & 30 & $77.2 \%$ & $87.3 \%$ & $10.1 \%$ & $83.7 \%$ & $90.8 \%$ & $7.1 \%$ & $83.9 \%$ & $87.5 \%$ & $7.4 \%$ \\
\hline
\end{tabular}

The results in Table 3 were expected. The more time a student spends on a single skill, the better they will do on it. The real question was whether after spending significant time using these tools, would the students develop motivation to use the tools in the future? Students' Lessons Learned Documents were used to investigate this. Students were asked to state opinions about each major document they worked on and to discuss any lessons they learned that they plan to carry into the future. They were also asked to comment on the quality of the course, effectiveness of advisors, and work ethic of teammates. Responses were compared between 2013, during which EE422 and EE464 were only loosely tied together, and 2014-2015, after EE422 material was formally connected with EE464 and continued to be applied in EE465. The feedback implies that after rigorous application of PM material throughout the entire project was required student appreciation for the material improved and intra-team conflicts were more reliably resolved. Specific analysis includes:

- Only $60 \%$ of the students from the 2013 cohort mentioned one of the documents besides Gantt Charts; whereas nearly 100\% of students in the 2014 - 2015 cohorts did.

- Of the comments offered by 2013 students, $42 \%$ were clearly positive. Of those offered by the $2014-2015$ cohorts, $84 \%$ were clearly positive.

- In $201336 \%$ of comments openly complained about 'busy work' related to at least one of the tools. Only one student in the 2014-2015 cohort made a similar comment.

- Of the 21 project teams supported between 2013 and 2015, two teams consisted of one team member who did not successfully complete their project, both in 2013.

- Of the remaining 19 successful teams, 2 made openly negative comments about a partner's work ethic; one in 2013 and one in 2015. Four teams discussed initial conflicts that were resolved, all four in 2014 or 2015.

It was expected that successful implementation of the PM material would have a positive effect on the students' projects, including: more projects should finish on-time, more projects should finish on-budget, and an increased ability to complete complex projects.

It is difficult to make a quantitative analysis of these results because detailed data was not maintained on projects before 2013. Therefore, faculty who had experience with projects before 
2013 were surveyed for qualitative feedback. Of the 7 faculty who had experience with the senior design sequence before 2013, 6 individuals responded. The survey asked participants to use the Likert scale shown below to answer the following questions.

$\begin{array}{llll}\text { Strongly Disagree (1) } & \text { Disagree (2) } & \text { Agree (3) } & \text { Strong Agree (4) }\end{array}$

Of the projects you are familiar with, these statements are true to what extent -

> Since 2013, the number of projects finished comfortably on-time has increased: $\quad 3.5$

> Since 2013, students are more likely to address/complete all project requirements: $\quad 3.2$

> Since 2013, the typical project difficulty/complexity has increased: $\quad 3.7$

$>$ Since 2013, team members seem to interact better (IE. better teamwork habits): $\quad 3.2$

The general consensus is that the implementation of PM material has had the expected effect. When this material is fully integrated, senior design projects are more likely to successfully complete projects on time, similar sized groups have the ability to handle larger, more complex projects, and team members interact with each other better (meaning more efficient teams). It is hope that the improved results are more similar to real industry projects.

\section{Lessons Learned}

A number of lessons were learned during this endeavor.

- The continuity and institutional memory that results from having one faculty member dedicated to the capstone sequence long term is of critical importance. For maximum benefit, this person should have both industry design and pedagogical/classroom experience. This person should strive to develop long-term relationships with potential project sponsors and project advisors, in order to maintain continuity from year to year.

- This continuity is important so that all stake-holders (students, faculty advisors, industry customers) know what to expect in order to anticipate required levels of commitment.

- It is important that the entire faculty have an agreed upon vision of what the senior capstone sequence should entail. The answers to questions such as 'should projects be more technically challenging or scaled to allow focus on the design process' and 'should projects be strictly design-based or are research projects acceptable' should be determined well in advance of the start of a particular semester at the very least. Ideally, this is established on a longer-term basis for the continuity benefits discussed above. This also ensures that the course instructor is better able to assess projects and students equitably; when one project is drastically different in scope from the other projects, grading that project can be quite difficult and the student perceptions of inequality can contribute to decreased levels of moral and enthusiasm for all projects.

- Formal guidelines, agreed upon by the faculty, aid in soliciting projects as well. Presenting a clear document to potential sponsors assists the sponsors develop appropriate project solicitations. Moreover, if a proposed project is unacceptable for 
some reason, this document is a formal tool that supports a discussion regarding modifications to the proposal in hopes that an acceptable project can be developed.

- It is important to have the same faculty responsible for all courses in the capstone sequence. When initially one faculty was assigned to the design courses and one to the project management course, the cohesion between assignments and schedules was not developed as well as it could have been. Once the same faculty took over all three courses, the cohesion has improved drastically.

- Students often tend to update Gantt Charts, Risk Resisters, and such immediately before they are due, rather than use them as tool consistently throughout the project. They begin to see these assignments as busy work. One method that seems to work (although no data has been collected) is to ensure the project advisor or instructor consistently requests to see "the visual" during meetings (ie: "the visual" could be the Gantt Chart if the students are discussing scheduling issues). This way students are forced to keep these documents up-to-date. When they are up-to-date, they can be used as useful tools and students begin to appreciate them more.

\section{Conclusions}

Improvements to the SDSU EECS senior design capstone sequence have been successfully implemented. Clear guidelines have been developed and agreed upon by faculty. These guidelines have provided a method by which to evaluate potential projects so that all projects meet ABET requirements and support a departmental preference toward industry-sponsored design projects. A clear understanding of the requirements has increased faculty motivation to solicit industry projects and allowed industry to submit better projects. Additionally, the guidelines and the formal IP statement from the university administration have been effective tools in soliciting more outside sponsors. The result has been a significant increase in the number of projects sponsored by industry.

As industry interests are rarely discipline-specific, the general increase of projects has included an increase in the amount of multidisciplinary projects solicited by industry. The formal intradepartmental agreement developed between the ME and EE departments has created a policy by which students from different departments can easily form official project-teams. These formal teams have been shown to be more effective at developing viable solutions than loosely joined groups each reporting to different faculty. By applying Problem Based Learning techniques and leveraging students' internal motivation to manage senior projects well, students' mastery of PM tools developed and student perception of project management was improved.

Overall, these changes have produced more realistic projects that expose students to an increased variety of real world design issues. The average complexity and size of projects have increased and project success rates have improved.

\section{References}


[1] ABET. [Online]. Available: http://www.abet.org/accreditation/accreditationcriteria/criteria-for-accrediting-engineering-programs-2016-2017/. [Accessed 1002 2017].

[2] Rutar, T. and Shuman, B., "A Modular Project Management Approach to Undergraduate Senior Design Projects," in ASEE Annual Conference, Vancouver, BC, 2011.

[3] Baumann, P and Al-Masoud, N., "Design of Experiment and Project Management Methodoologies Support a Senior Design Research Course and Its Assessment," in ASEE Annual Conference, Louisville, KY, 2010.

[4] P. Ravikumar, "Assess and Improving a Senior Design Project Course for Undergraduates in Mechanical Engineering Based on New ABET Guidelines," in ASEE Annual Conference, Albuquerque, NM, 2001.

[5] Carroll, B., Weems, B., and Khalili, B. , "A Professional Practices Course in Computer Science and Engineering," in ASEE Annual Conference, Seattle, WA, 2015.

[6] Lawanto, O., Cromwell, M., and Febrian, A., "Student's Self-Regulation in Managing Their Castone Senior Design Projects," in ASEE 123rd Annual Conference and Exposition, New Orleans, LA, 2016.

[7] Townsend, V. and Urbanic, J., "Project Management Takes Flight," in ASEE Annual Conference, Indianapolis, IN, 2014.

[8] Prince, M. and Felder, R., "The Many Faces of Inductive Teaching and Learning," Journal of College Science Teaching, 2007.

[9] Hughes, I. and Overton, T., "Key Aspects of Learning and Teaching in Science and Engineering.," A handbook for teaching and learning in higher education, 3rd Edition, 2008.

[10] P. Dr. Lewis Brown, Interviewee, Dean of Engineering, South Dakota State University. [Interview]. 24 Jan 2017.

[11] A. Vavreck, "Project Management Appied to Student Design Projects," in ASEE Annual Conference, Montreal, Canada, 2002.

[12] Brakin, P. and Gibson, D., "Capstone Design Projects with Industry: Emphasizing Teaming and Management Tools," in ASEE Annual Conference, Portland, OR, 2005.

[13] P. M. Institute, A Guide to the Project Management Body of Knowledge, 5th ed, Project Management Institute, 2013. 